\title{
Financing U.S. Graduate Medical Education: A Policy Position Paper of the Alliance for Academic Internal Medicine and the American College of Physicians
}

\author{
Renee Butkus, BA; Susan Lane, MD; Alwin F. Steinmann, MD; Kelly J. Caverzagie, MD; Thomas G. Tape, MD; Susan T. Hingle, MD; \\ Darilyn V. Moyer, MD; and the Alliance for Academic Internal Medicine and American College of Physicians Graduate Medical \\ Education Task Forces, for the Health and Public Policy Committee of the American College of Physicians*
}

In this position paper, the Alliance for Academic Internal Medicine and the American College of Physicians examine the state of graduate medical education (GME) financing in the United States and recent proposals to reform GME funding. They make a series of recommendations to reform the current funding system to better align GME with the needs of the nation's health care workforce. These recommendations include using Medicare GME funds to meet policy goals and to ensure an adequate supply of physicians, a proper specialty mix, and appropriate training sites; spreading the costs of financing GME across the health care system; evaluating the true cost of training a resident and establishing a single per-resident amount; increasing transparency and innovation; and ensuring that primary care residents receive training in well-functioning ambulatory settings that are financially supported for their training roles.

Ann Intern Med. 2016;165:134-137. doi:10.7326/M15-2917 www.annals.org For author affiliations, see end of text.

This article was published at www.annals.org on 3 May 2016
G raduate medical education (GME) is the process by which graduate medical students become competent practitioners in a particular field of medicine. The GME programs, known as residencies and fellowships, allow trainees to develop the knowledge, skills, and attitudes required for independent practice. Therefore, GME plays a major role in addressing the nation's workforce needs because it is the ultimate determinant of physician output. Recognizing the important public good GME provides to the nation and, by extension, its help in ensuring needed care to patients, the federal government is the largest explicit provider of GME funding, contributing nearly $\$ 15$ billion annually. Most of the government's funding comes from Medicare. Currently, the types and numbers of residents trained in teaching hospitals are largely determined by the staffing needs of the particular hospital and the number

See also:

Web-Only

Appendix: Full Position Paper of funded positions established by a "cap" in the Balanced Budget Act of 1997, which froze the number of funded GME positions at 1996 levels for existing training programs. Although hospitals that have never been assigned a resident cap can start new programs and have 5 years to establish one, the existing caps on the current number of Medicare-funded GME positions available make it impossible to fund the number of GME training positions necessary to slow or reverse the growing shortage of primary care physicians and other specialists. With sharply increasing numbers of graduating allopathic and osteopathic medical students and looming physician workforce shortfalls, especially in primary care, the current bottleneck in the physician supply chain is the fixed number of funded GME positions for residency training (1).

Much attention has been focused on Medicare's support of GME. Its costs are recognized by Medicare under 2 mechanisms: direct GME (DGME) payments to hospitals for residents' stipends, faculty salaries, administrative costs, and institutional overhead; and an indirect medical education (IME) adjustment developed to compensate teaching hospitals for the higher costs associated with teaching, the involvement of residents in

\footnotetext{
* This paper, written by Renee Butkus, BA; Susan Lane, MD; Alwin F. Steinmann, MD; Kelly J. Caverzagie, MD; Thomas G. Tape, MD; Susan T. Hingle, MD; Darilyn V. Moyer, MD; and the Alliance for Academic Internal Medicine and American College of Physicians Graduate Medical Education Task Forces, was developed for the Health and Public Policy Committee of the American College of Physicians. Individuals who served on the Health and Public Policy Committee from initiation of the project until its approval were Darilyn V. Moyer, MD (Chair)t; Douglas M. DeLong, MD (Vice Chair)t; Sue S. Bornstein, MD ;

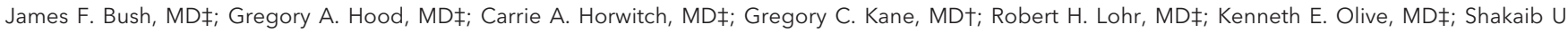

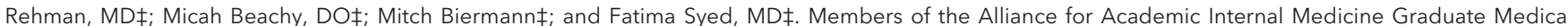

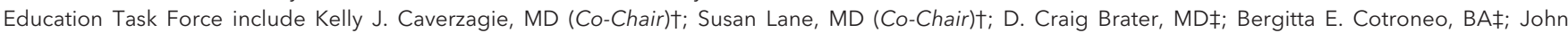
Donnelly, MD†; Jeffrey Jaeger, MD†; Heather S. Laird-Fick, MD†; John P. Moriarty, MD†; Darilyn V. Moyer, MD†; Niraj Sharma, MDł; Alwin F. Steinmann, MD†; Sara L. Wallach, MDł; and Richard M. Wardrop III, MD, PhD†. Members of the American College of Physicians Graduate Medical Education Task Force include Thomas G. Tape, MD (Co-Chair)t; Darilyn V. Moyer, MD (Co-Chair)t; Michael S. Bronze, MDt; Thomas G. Cooney, MDt; Douglas M. DeLong, MDt; Gustavo R. Heudebert, MDt; Susan T. Hingle, MDt; Gregory C. Kane, MDt; Susan Lane, MDt; Mark A. Levine, MDt; Wickliffe J. Many Jr., MDt; Lawrence G. Smith, MDt; and Sara L. Wallach, MDł. Approved by the ACP Health and Public Policy Committee in October 2015 and the ACP Board of Regents and the AAIM Board of Directors in January 2016.

$\dagger$ Author

‡ Nonauthor contributor.
} 
patient care, and the severity of illness of patients who require the specialized services that teaching hospitals provide. In a 2010 report to Congress, the Medicare Payment Advisory Commission stated that $50 \%$ of the IME adjustment represents overpayment to hospitals and recommended using those funds to establish a performance-based GME program. Since then, IME has been frequently identified as an opportunity for deficit reduction. Calls for increased transparency and accountability for training an adequate supply of physicians with the skills necessary to meet the nation's health care needs have been made. In 2014, the Institute of Medicine (IOM) released a report recommending that Congress overhaul the federal financing and governance of $G M E$, including the creation of new infrastructure for fund distribution and research into improved payment models. Many applauded the IOM for its call for transformation and innovation in GME, but the report also sparked criticism. Although it called for maintaining Medicare's current level of support for GME, the net effect would be a reduction in payments for existing GME programs because the funds would not only support 2 new federal entities and probably absorb the Children's Hospitals GME Payment Program costs, they would also be distributed to facilitate innovation.

Furthermore, the report did not recognize the looming physician shortage, especially in primary care, declaring that there are "no credible data" to support this claim (2). Although workforce projections are unlikely to precisely predict shortages, trends can guide determination and preparation for future challenges. In fact, several projections indicate a shortfall of physicians in both primary and specialty care (3-18). The IOM rejected the evidence of existing and looming shortages, stating that these projections often assume historic provider-patient ratios, and called for a more coordinated, affordable, and patient-centered health care system through expanded roles for advanced practice clinicians, redesign of care delivery, and other innovations in health care delivery (including telehealth and electronic communication). Although such a system would be ideal, transformation will take time and making future workforce decisions based on a model that has not been achieved or tested would be unwise. An adequate workforce to assist in the transition to, and training of, physicians in the model health delivery system to which the nation aspires will also be necessary.

In 2010 and 2011, the Alliance for Academic Internal Medicine (AAIM) and the American College of Physicians (ACP) individually called for GME reform and alignment of GME with the nation's health care workforce needs $(19,20)$. Since then, nearly 50 billion Medicare dollars have been spent to train physicians without consideration of those needs. Our organizations, with a combined membership of 151627 internists, internal medicine subspecialists, medical students, residents, and fellows, feel strongly that sufficient GME funding and a strategic approach to physician workforce projections (as they relate to GME financing) is critical. The imperative of deficit reduction also suggests that fund- ing for GME could be more effectively targeted and prioritized to fields with the greatest and most critical needs, with the goal of training more physicians to meet national workforce needs.

The GME system should ensure that the nation has an adequate supply of the types of physicians needed to treat patients; that they enter the workforce with the knowledge, skills, and attitudes required to provide the highest quality care; and that all Americans have access to such care. The nation will not be able to expand access, improve outcomes, and decrease expenditures without a national health care workforce policy and the appropriate direction of funding to achieve these goals.

\section{MeTHODS}

This policy paper was drafted by the AAIM and ACP Graduate Medical Education Task Forces for the ACP Health and Public Policy Committee, which is charged with addressing issues that affect the health care of the U.S. public and the practice of internal medicine and its subspecialties. The authors reviewed available studies, reports, policy documents, and surveys on GME from PubMed, Google Scholar, Web sites, and other sources. Recommendations were based on reviewed literature and input from the ACP Board of Governors, Board of Regents, Council of Early Career Physicians, Council of Resident/Fellow Members, Council of Student Members, and Council of Subspecialty Societies; and the AAIM Advocacy Committee, Education Committee, and Board of Directors. The policy paper and related recommendations were reviewed and approved by the ACP Health and Public Policy Committee in October 2015 and the ACP Board of Regents and the AAIM Board of Directors in January 2016. Financial support for the development of this position paper comes exclusively from the ACP operating budget.

\section{AAIM And ACP Position Statements ANd RECOMMENDATIONS}

The following statements represent the official policy positions and recommendations of the AAIM and ACP. The rationale for each is provided in the full position paper (see the Appendix, available at www .annals.org).

1. The federal government should maintain its commitment to GME. Payment of Medicare GME funds should be linked to the ability of the GME system to meet the nation's health care workforce needs. Payments should be used to meet policy goals to ensure adequate supply, specialty mix, and training sites.

2. All payers should be required to contribute to a financing pool to support residencies that meet the nation's policy goals related to supply, specialty mix, and training sites.

3. A thorough evaluation of the true cost of training physicians is required before any decisions are made about how GME funds are distributed. 
4. Direct GME and IME should be combined into a single, more functional payment program that is designed to meet the needs of patients and populations.

5. Graduate medical education funding should be transparently allocated to ensure that funds are appropriately designated toward activities related to the educational mission of teaching and training residents and fellows. Graduate medical education funds should follow trainees into all training settings, rather than being linked to the location of service relative to the sponsoring institutions.

6. Graduate medical education caps should be lifted as needed to permit training an adequate number of primary care physicians, including internal medicine specialists, and physicians in other specialties facing shortages, including internal medicine-pediatrics and many internal medicine subspecialties.

7. The concept of a performance-based GME payment system is worth exploring. Such a system should be thoughtfully developed and considered in a deliberate way to ensure that goals are achieved without destabilizing the system of physician training. We recommend the following:

a. Measures should be developed by appropriate stakeholders, including physicians involved in GME training.

b. All measures must be carefully developed and thoroughly evaluated before they are implemented.

c. Institutions must be allowed adequate time to make necessary changes to their training programs before financial incentives are introduced.

d. Revised GME funding should account for the costs of transitioning into a performance-based GME system, and once done, clear-cut financial transparency and incentives must be delineated.

e. The performance measures should be evidencebased and align with the Accreditation Council for Graduate Medical Education (ACGME) requirements. The core mission of individual programs should be considered. Producing a certain number of physicians trained in a certain specialty or subspecialty should not be a specific performance metric.

$f$. A careful study of unintended consequences should be done to ensure that programs are not unfairly disadvantaged.

g. Regular evaluations of the measures should be implemented to avoid adverse unintended consequences, ensure that the goals of implementing such a system are achieved, and confirm that the measures remain relevant over time.

8. Pilot projects should be introduced to evaluate potential changes to GME funding, including a performance-based GME payment system, and to promote innovation in GME by providing training programs with the resources necessary to experiment with innovative training models. Pilot projects should not be funded using existing GME funding.

9. Internal medicine and internal medicinepediatrics residents should receive primary care training in well-functioning ambulatory settings that are financially supported for their training roles. Barriers should be removed to encourage programs to train residents in nonhospital settings, promote innovation in training, and facilitate clinical learning experiences that promote primary care.

\section{Conclusion}

A concerted effort must be made to ensure that the nation has an adequate supply of the types of physicians needed to treat patients, that they enter the workforce with the knowledge and skills required to provide the highest quality care in an ever-evolving delivery system, and that all Americans have access to such care. Graduate medical education funding must be reformed to include all health care payers and to ensure that payments better correlate with the funds they are intended to cover, address physician workforce needs, and provide an optimal training environment so that residents gain the skills necessary to care for the needs of society.

From the American College of Physicians, Washington, DC; Saint Joseph Hospital, Denver, Colorado; University of Nebraska Medical Center, Omaha, Nebraska; Southern Illinois University School of Medicine, Springfield, Illinois; Temple University, University of Pennsylvania, and Thomas Jefferson University, Philadelphia, Pennsylvania; Cristiana Care Health System, Newark, Delaware; Michigan State University, Lansing, Missouri; Yale-New Haven Hospital, New Haven, Connecticut; Brigham and Women's Hospital, Boston, Massachusetts; St. Francis Medical Center, Trenton, New Jersey; University of North Carolina, Chapel Hill, North Carolina; University of Oklahoma Health Sciences Center, Oklahoma City, Oklahoma; Oregon Health \& Science University, Portland, Oregon; Bassett Healthcare Network, Cooperstown, New York; University of Alabama at Birmingham School of Medicine, Birmingham, Alabama; University of Vermont Medical Center, Burlington, Vermont; and Northwell Health, Great Neck, New York.

Financial Support: Financial support for the development of this guideline comes exclusively from the ACP operating budget.

Disclosures: Dr. Lohr reports being a member of the ACP Board of Regents. Dr. Tape reports personal fees from ACP, UnitedHealthcare, and the University of Nebraska Medical Center outside the submitted work. Dr. Wallach reports stocks (Pfizer) outside of the submitted work. Authors not named here have disclosed no conflicts of interest. Disclosures can be viewed at www.acponline.org/authors/icmje/ConflictOf InterestForms.do?msNum=M15-2917.

Requests for Single Reprints: Renee Butkus, BA, American College of Physicians, 25 Massachusetts Avenue NW, Suite 700, Washington, DC 2001; e-mail, RButkus@acponline .org.

Current author addresses and author contributions are available at www.annals.org. 


\section{References}

1. Kane GC, Grever MR, Kennedy JI, Kuzma MA, Saltzman AR, Wiernik $\mathrm{PH}$, et al. The anticipated physician shortage: meeting the nation's need for physician services. Am J Med. 2009;122:1156-62. [PMID: 19958898] doi:10.1016/j.amjmed.2009.07.010

2. Eden J, Berwick D, Wilensky G, eds; Committee on the Governance and Financing of Graduate Medical Education; Board on Health Care Services; Institute of Medicine. Graduate Medical Education That Meets the Nation's Health Needs. Institute of Medicine. Washington, DC: National Academies Pr; 2014.

3. Colwill JM, Cultice JM, Kruse RL. Will generalist physician supply meet demands of an increasing and aging population? Health Aff (Millwood). 2008;27:w232-41. [PMID: 18445642] doi:10.1377/hlthaff .27.3.w232

4. Petterson SM, Liaw WR, Phillips RL Jr, Rabin DL, Meyers DS, Bazemore AW. Projecting US primary care physician workforce needs: 2010-2025. Ann Fam Med. 2012;10:503-9. [PMID: 23149526] doi:10 .1370/afm.1431

5. IHS; Association of American Medical Colleges. The complexities of physician supply and demand: projections from 2013 to 2025: final report. Washington, DC: Association of American Medical Colleges; 2015. Accessed at www.aamc.org/download/426242/data /ihsreportdownload.pdf on 21 April 2016.

6. U.S. Department of Health and Human Services; Health Resources and Services Administration; National Center for Health Workforce Analysis. Projecting the supply and demand for primary care practitioners through 2020. Rockville, MD: U.S. Department of Health and Human Services; 2013. Accessed at http://bhpr.hrsa.gov/health workforce/supplydemand/usworkforce/primarycare on 21 April 2016.

7. Center for Health Workforce Studies. Forecasting allergy and immunology physician supply and demand through 2024. Rensselaer, NY: Center for Health Workforce Studies; 2006.

8. Fye WB. Cardiology workforce: a shortage, not a surplus. Health Aff (Millwood). 2004;Suppl Web Exclusives:W4-64-6. [PMID: 15451974]

9. Duke E; Health Resources and Services Administration. Report to Congress: the critical care workforce: a study of the supply and demand for critical care physicians. Rockville, MD: Health Resources and Services Administration; 2006.
10. American College of Emergency Physicians. America's emergency care environment: a state-by-state report card: 2014 edition. Irving, TX: American College of Emergency Physicians; 2015. Accessed at www.emreportcard.org/uploadedFiles/EMReport Card2014.pdf 10 September 2015.

11. Rizza RA, Vigersky RA, Rodbard HW, Ladenson PW, Young WF Jr, Surks MI, et al. A model to determine workforce needs for endocrinologists in the United States until 2020. Endocr Pract. 2003;9: 210-9. [PMID: 12917063]

12. Lynge DC, Larson EH, Thompson MJ, Rosenblatt RA, Hart LG. A longitudinal analysis of the general surgery workforce in the United States, 1981-2005. Arch Surg. 2008;143:345-50. [PMID: 18427021] doi:10.1001/archsurg.143.4.345

13. The Donald W. Reynolds Foundation and the John A. Hartford Foundation. Grantee's final progress report summary: the status of geriatrics workforce study. New York: American Geriatrics Society; 2009. Accessed at www.americangeriatrics.org/files/documents /gwps/ADGAP\%20Final\%20Report,\%20Phase\%20III,\%202006 -2009\%20for\%20web.pdf on 10 August 2015.

14. Erikson C, Salsberg E, Forte G, Bruinooge S, Goldstein M. Future supply and demand for oncologists: challenges to assuring access to oncology services. J Oncol Pract. 2007;3:79-86. [PMID: 20859376] doi:10.1200/JOP.0723601

15. Deal CL, Hooker R, Harrington T, Birnbaum N, Hogan P, Bouchery $\mathrm{E}$, et al. The United States rheumatology workforce: supply and demand, 2005-2025. Arthritis Rheum. 2007;56:722-9. [PMID: 17328042]

16. Scully JH, Wilk JE. Selected characteristics and data of psychiatrists in the United States, 2001-2002. Acad Psychiatry. 2003;27:24751. [PMID: 14754847]

17. Schubert A, Eckhout G Jr, Tremper K. An updated view of the national anesthesia personnel shortfall. Anesth Analg. 2003;96:20714, table of contents. [PMID: 12505954]

18. Kim, WJ. Child and adolescent psychiatry workforce: a critical shortage and national challenge. Academic Psychiatry. 2003;27:27782.

19. Alliance for Academic Internal Medicine. Principles for Medicare GME reform. Alexandria, VA: Alliance for Academic Internal Medicine; 2010.

20. Butkus R; American College of Physicians. Aligning GME policy with the nation's health care workforce needs. Philadelphia: American College of Physicians; 2011. 
Current Author Addresses: Ms. Butkus: American College of Physicians, 25 Massachusetts Avenue NW, Suite 700, Washington, DC 2001.

Dr. Lane: Stony Brook Medicine, 101 Nicolls Road, Stony Brook, NY 11794.

Dr. Steinmann: Saint Joseph Hospital, 1960 North Ogden Street, Suite 300, Denver, CO 80218.

Drs. Caverzagie and Tape: Department of Internal Medicine, University of Nebraska Medical Center, 42nd Street and Emile Street, Omaha, NE 68198.

Dr. Hingle: Southern Illinois University School of Medicine, 801 North Rutledge Street, Mail Code 9628, Springfield, IL 62794.

Dr. Moyer: Department of Medicine, Temple University, 3401 North Broad Street, 8 Parkinson Pavilion, Philadelphia, PA 19140.

Dr. Donnelly: Christiana Care Health System, John H. Ammon Medical Education Center, 4475 Ogletown-Stanton Road, Suite 2E70, Newark, DE 19718.

Dr. Jaeger: University of Pennsylvania, 3701 Market Street, 7th Floor, Suite 760, Philadelphia, PA 19104.

Dr. Laird-Flick: Michigan State University, 788 Service Road, B301 Clinical Center, East Lansing, MI 48824.

Dr. Moriarty: Yale-New Haven Hospital, 1450 Chapel Street, New Haven, CT 06511.

Dr. Sharma: Brigham and Women's Hospital, 75 Francis Street, Mail Code PBB-B416, Boston, MA 02115.

Dr. Wallach: St. Francis Medical Center, 601 Hamilton Avenue, Trenton, NJ 08629.

Dr. Wardrop: Department of Pediatrics, University of North Carolina, 260 MacNider Building, CB 7220, Chapel Hill, NC 27599.

Dr. Bronze: Department of Internal Medicine, University of Oklahoma Health Sciences Center, 920 Stanton Young Boulevard, PO Box 26901, WP1140, Oklahoma City, OK 73126.

Dr. Cooney: Department of Medicine, Oregon Health \& Science University, Mail Code OP30, 3181 Southwest Sam Jackson Park Road, Portland, OR 97239.

Dr. DeLong: Bassett Healthcare Network, 1 Atwell Road, Cooperstown, NY 13326.

Dr. Heudebert: University of Alabama at Birmingham School of Medicine, Faculty Office Tower Room 730, 510 20th Street South, Birmingham, AL 35294.

Dr. Kane: Thomas Jefferson University, Sidney Kimmel Medical College, 1025 Walnut Street, Philadelphia, PA 19107.

Dr. Levine: University of Vermont Medical Center, 111 Colchester Avenue, Burlington, VT 05401.

Dr. Many: University of Alabama at Birmingham School of Medicine, 2119 East South Boulevard, Suite 304, Montgomery, AL 36116.

Dr. Smith: Northwell Health, 145 Community Drive, Great Neck, NY 11021.

Author Contributions: Conception and design: R. Butkus, K.J. Caverzagie, D.M. DeLong, G.R. Heudebert, S.T. Hingle, G.C. Kane, H.S. Laird-Fick, S.W. Lane, M.A. Levine, J.P. Moriarty, D.V. Moyer, N. Sharma, L.G. Smith, T.G. Tape.

Analysis and interpretation of the data: M.S. Bronze, R. Butkus, K.J. Caverzagie, T.G. Cooney, G.R. Heudebert, S.W. Lane, M.A. Levine, J.P. Moriarty, D.V. Moyer, S.L. Wallach.

Drafting of the article: R. Butkus, G.R. Heudebert, S.T. Hingle, G.C. Kane, H.S. Laird-Fick, S.W. Lane, M.A. Levine, J.P. Mori- arty, D.V. Moyer, N. Sharma, L.G. Smith, A. Steinmann, T.G. Tape.

Critical revision for important intellectual content: R. Butkus, K.J. Caverzagie, T.G. Cooney, D.M. DeLong, G.R. Heudebert, S.T. Hingle, J.R. Jaeger, G.C. Kane, H.S. Laird-Fick, S.W. Lane, M.A. Levine, W.J. Many, J.P. Moriarty, D.V. Moyer, N. Sharma, T.G. Tape, S.L. Wallach, R.M. Wardrop.

Final approval of the article: M.S. Bronze, R. Butkus, K.J. Caverzagie, T.G. Cooney, D.M. DeLong, J. Donnelly, G.R. Heudebert, S.T. Hingle, J.R. Jaeger, G.C. Kane, H.S. Laird-Fick, S.W. Lane, M.A. Levine, W.J. Many, J.P. Moriarty, D.V. Moyer, N. Sharma, L.G. Smith, A. Steinmann, T.G. Tape, S.L. Wallach, R.M. Wardrop.

Administrative, technical, or logistic support: R. Butkus.

Collection and assembly of data: M.S. Bronze, R. Butkus, S.T. Hingle, S.W. Lane, J.P. Moriarty, D.V. Moyer.

\section{Appendix: Financing U.S. Graduate Medical Education: Policy Position of THE Alliance for ACADEmic InTERnal Medicine And the American College of Physicians \\ Background \\ GME in the United States}

Graduate medical education is formal clinical training provided by approved residency and fellowship programs to physicians who have received an MD or a DO degree (or an international equivalent). It involves a 3- to 7-year training period after completion of medical school in which physicians are directly supervised as they progressively assume more responsibility for patient care. This training is mandatory for certification. In the United States, training programs must be accredited by the ACGME or approved by the Commission on Osteopathic College Accreditation. Osteopathic programs are in the process of transitioning to accreditation by the ACGME. Teaching hospitals generally serve as the sponsors and main training sites for most residency programs, although training can occur in other inpatient and ambulatory settings in various community-based settings.

In the 2013-2014 academic year, 120108 residents were enrolled in ACGME-accredited residency programs. During this time, 693 institutions sponsored residency programs, of which 377 were considered multisite sponsors that sponsored programs in more than 1 specialty or affiliated subspecialties. Internal medicine had $24 \%$ of the total number of residents enrolled in these residency programs, with $11 \%$ in family medicine, $8.9 \%$ in pediatrics, and $1.9 \%$ in internal medicine-pediatrics. Of note, $42 \%$ of these internal medicine residents were international medical graduates (21).

\section{Overview of GME Financing System}

Graduate medical education financing is provided primarily to teaching hospitals from federal and state 
Appendix Figure. Total Medicare GME funding in 2012.

Total Medicare GME funding (2012)

$\sim \$ 9.6$ billion
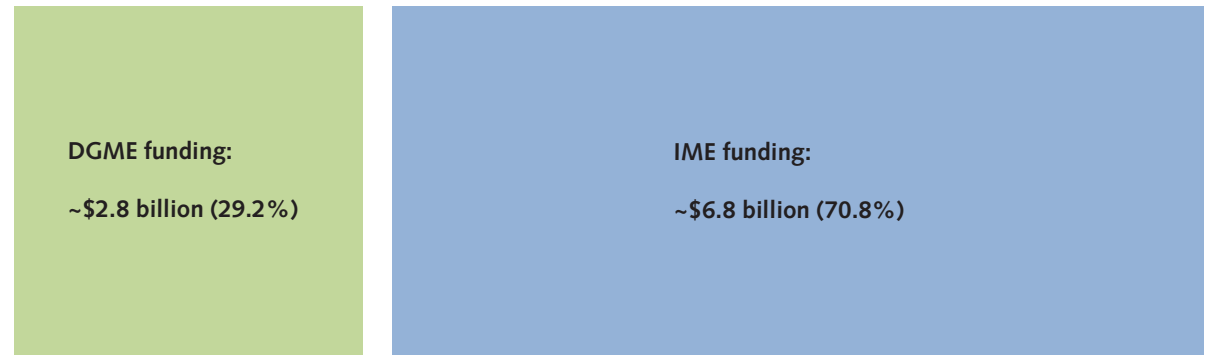

DGME funding goes toward

- stipends for residents;

- faculty salary;

- administrative costs; and

- institutional overhead.

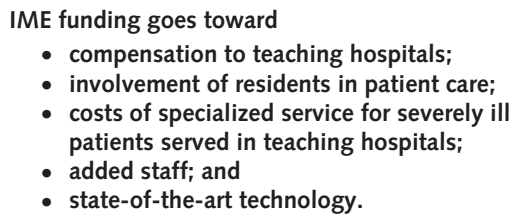

- state-of-the-art technology.

$\mathrm{DGME}=$ direct graduate medical education; $\mathrm{GME}=$ graduate medical education; $\mathrm{IME}=$ indirect medical education.

government payers and indirectly from private payers through the higher payments negotiated with teaching hospitals. Although teaching hospitals account for only $6 \%$ of the nation's hospitals, they provide $20 \%$ of all U.S. hospital care, $25 \%$ of all Medicaid hospitalizations, and $41 \%$ of all hospital charity care (22). The primary federal sources of GME funding are Medicare, Medicaid, the U.S. Department of Veterans Affairs, the Health Resources and Services Administration (HRSA) Title VII health professions programs, the Children's Hospitals GME Payment Program, and the U.S. Department of Defense. Other sources include private payers (although this is rarely explicit), philanthropy, and institutional resources.

Medicare. The largest single explicit financing source for GME is Medicare. Medicare subsidizes education and training for more than 90000 residents in more than 1100 hospitals. In 2012, Medicare expenses associated with GME were approximately $\$ 9.6$ billion (2). Such funding is provided to teaching hospitals with no restrictions on which types of physicians are trained; however, the number of funded positions has been capped at 1996 levels by the Balanced Budget Act of 1997. Hospitals that have never been assigned a resident cap can start new programs and have 5 years to establish a Medicare cap, which has allowed for a modest expansion of Medicare GME positions.

The costs of GME are recognized by Medicare under 2 mechanisms: DGME payments to hospitals for residents' stipends, faculty salaries, administrative costs, and institutional overhead; and an IME adjustment developed to compensate teaching hospitals for the higher costs associated with teaching, the involve- ment of residents in patient care, and the severity of illness of patients who require the specialized services that are available in teaching hospitals (Appendix Figure).

Direct GME payments are based on a hospitalspecific per-resident amount (PRA). The PRA is calculated by taking the DGME costs incurred by a teaching hospital during a base period (1984 or 1985) and dividing it by the number of full-time equivalent residents during that year. The PRA is updated annually for inflation. Payments for primary care residents are slightly higher because in 1994 and 1995, only their payments were updated for inflation. In addition, the DGME amount for training beyond residents' initial board certification in their first specialty is reduced by $50 \%$ (except for geriatrics). Medicare capped the number of residents it supports to the number in a hospital's most recent cost report period ending on or before $31 \mathrm{De}$ cember 1996 as a result of changes made in the Balanced Budget Act of 1997 (23).

Indirect medical education payments are tied to a hospital's Medicare inpatient volume and case mix along with its training program size (subject to its resident cap number). The payments, based on a formula, are an adjustment to Medicare's inpatient payment rates and vary based on each hospital's ratio of residents to beds. The current IME rate is 5.5\%. Based on this rate, the IME adjustment would result in a $5.5 \%$ increase in a teaching hospital's Medicare reimbursement per 0.1 increase in the resident-to-bed ratio (1 resident to 10 beds). Medicare IME payments were more than double the Medicare DGME payments in 2010 (24). 
Medicaid and Other State Support. States can support GME through their Medicaid programs, although the amounts and mechanisms of support vary substantially. Medicaid's contribution to GME expenses is considerable-it comprised an estimated $\$ 3.9$ billion in support from federal and state funds in 2012 (2). Medicaid GME funding has become extremely vulnerable due to recent financial constraints in state budgets. A 2012 survey found that 42 states and the District of Columbia provided GME payments under their Medicaid program. Five states reported having recently considered ending GME Medicaid payments (25). Some states have dedicated programs to support GME, whereas others facing shortages have recently increased their support. Maryland has collected money from private insurance plans to help finance GME since 1974. In 2014, the New Mexico legislature redirected state Medicaid funds to help open new primary residency slots in underserved areas of the state (26). Texas lawmakers granted an additional \$30 million (\$97 million total) for GME in its 2014-2015 state budget (27).

Other Federal Support. The U.S. Department of Veterans Affairs funds more than 10000 resident fulltime equivalent positions ( $\$ 1.4$ billion annually). The U.S. Department of Defense supports the education and training of about 3000 residents. The Children's Hospitals GME Payment Program, administered by HRSA, provides funds (which have decreased in recent years to $\$ 265$ million for the 2015 fiscal year) that support direct and indirect GME costs at children's teaching hospitals. The Teaching Health Center (THC) GME program also supports direct and indirect costs of GME for about 550 residents through HRSA, but unlike other funding, support from these sources is appropriationsbased (28). Start-up costs for new residency programs, including those for program directors and residency coordinators, and facility-related costs, including construction of conference and call rooms, are high; without a guaranteed funding stream, cost and uncertainty about future appropriations represent a major deterrent for THCs. Some Title VII grants administered by HRSA are used to support residency programs in primary care and geriatrics; however, funds for these programs are modest and appropriations-based, which often makes them vulnerable and unpredictable.

Private Funding. Graduate medical education is also supported by private sources, including hospitals, universities, philanthropy, and industry gifts and grants. Although the amount is not well-documented, it may be significant. Private insurers also support GME indirectly through the higher rates they pay to teaching hospitals than other hospitals. The actual amount is difficult to estimate because the proportion attributed to education is not specifically identified in these payments (29). Despite the 1997 cap by Congress on the number of Medicare-supported residency positions, between academic years 2003-2004 and 2012-2013, the number of trainees increased by $17.5 \%$ (from 100176 to 117717 ), indicating that there is substantial private funding for GME (2). Some of the increase involves Medicare-funded positions, yet the portion funded privately has changed over time. After a few years of relative stability following the passage of the Balanced Budget Act, the number of U.S. trainees grew by nearly 17000 positions by 2010, with about $27 \%$ of these being funded by Medicare and $73 \%$ being funded through other sources. By 2013, that number had grown to more than 23000 and the percentage with Centers for Medicare \& Medicaid Services funding increased to $46 \%$. This may have to do more with GMEnaive hospitals starting new programs, especially in association with newly formed medical schools $(30,31)$.

\section{Problems With the Current GME Funding System \\ Lack of Consideration of Workforce Needs}

Graduate medical education funding is not linked to current or future health care workforce needs. Although Medicare GME funds are intended to help develop the future physician workforce, teaching hospitals are not required to consider local, regional, or national workforce needs. The types of residents trained in teaching hospitals are largely determined by the particular hospital's staffing needs and the number of funded positions set by the cap in 1997. Despite the increasing need for primary care physicians, hospitals have largely favored less costly, higher revenuegenerating specialty training when adding GME positions (32).

The existing caps on the number of Medicarefunded GME positions available also make it impossible to fund the number of GME training positions necessary to slow or reverse the growing shortages of primary care physicians and other specialists. With sharply increasing numbers of allopathic and osteopathic medical students and looming physician workforce shortfalls, especially in primary care, the current bottleneck in the physician supply chain is the number of residency positions.

Our organizations have long been concerned about the shortage of primary care physicians in the United States, particularly the supply of internal medicine physicians who apply scientific knowledge and clinical expertise to the diagnosis, treatment, and compassionate care of adults across the spectrum of health and complex illness. The projected growth in demand for services necessary for the elderly population is expected to be substantially higher than the growth for pediatric services because the population younger than age 18 is projected to grow by only $5 \%$ by 2025 , whereas the population aged 65 years or older is projected to grow by $46 \%$ (5). The Medicare population is 
expected to grow from 53.8 million in 2014 to 82 million in 2030 (33). The skills of internal medicine physicians will be increasingly needed to care for an aging population with a growing incidence of chronic disease and multiple comorbidities. Health care systems dominated by primary care providers have better outcomes at lower costs (34), yet the nation faces a severe shortage of primary care physicians-estimated to be 12500 to 31100 by 2025 (5).

The reasons behind this decline in the supply of primary care physicians are multifaceted and complex. Key factors include the rapid increase in medical education debt, decreased income potential for primary care physicians compared with specialists, and increased administrative requirements that have caused great dissatisfaction with the current practice environment. Although studies show that debt is near the bottom of factors affecting specialty choice, when combined with other factors, especially differential in earnings over a lifetime, debt may have a major effect on specialty choice $(35,36)$. In 2014, the average medical student graduate was $\$ 176348$ in debt (37). During residency training, the average resident works 40 to 80 hours each week and earns a median first-year salary of $\$ 50214$. The average education debt and salary during training are the same for all residents, but the salary when entering practice varies greatly by specialty. The gap between the median income of a primary care physician and that of a subspecialist is $\$ 135000$. This amounts to a $\$ 3.5$ million difference over a 35- to 40-year career and decreases the odds of choosing primary care by nearly $50 \%$ (38). Of note, there is significant variation in salary based on specialty, with procedural subspecialists at the higher end and cognitive-based subspecialists at the lower end. These barriers must be addressed simultaneously and swiftly for the nation to meet the demand for the number of primary care physicians necessary to care for the U.S. population.

Although it is imperative that the number and proportion of primary care physicians be increased, the aging of the population will demand a sufficient number of physicians, including geriatricians and many other internal medicine subspecialties, trained in the complex medical problems typical of that age group. In addition, other specialties are facing shortages, including general surgery $(5,10,12,13)$.

Of note, as the general population rapidly ages, so does the physician population. According to the Association of American Medical Colleges 2015 State Physician Workforce Data Book (39), 29.4\% of the physician population (248 572 physicians) is aged 60 years or older. The work product of retiring versus newly minted physicians should not be considered a 1:1 equivalency because new medical school graduates are more likely to take employed positions and are increasingly seek- ing quality work-life balance, therein working fewer hours than older physicians. Productivity will also be affected by the increasing number of female physicians in the workforce. Women represent a growing portion of U.S. medical school graduates, increasing from nearly $20 \%$ in 1980 to $47 \%$ in 2014 . They are more likely to work part-time and take extended leave than their male counterparts. In addition, female physicians work an average of 7.4 hours fewer per week than male physicians (40).

\section{Geographic Disparities and Maldistribution}

Beyond overall shortages, the geographic disparities in the number of Medicare-funded GME positions among states and the amount that is paid per resident are large. Teaching hospitals, and therefore residents, are unevenly distributed across the United States. This is important because there is a positive correlation between the site of residency training and where a physician ultimately chooses to practice medicine (41). Physician maldistribution results in gaps in access to care and health disparities experienced by specific regions, races, and income groups (38).

Resident-to-population ratios range from 1.63 residents per 100000 persons in Montana to 77.13 residents per 100000 persons in New York (42). Since the resident caps went into effect in 1997, population growth and shifts in where people reside have been noteworthy. Between 2010 and 2014, seven of the ten fastest growing areas were southern and western states. Texas has led the nation in population growth for a decade, with an increase of 450000 people between 2013 and 2014 alone (43). Between 2000 and 2010, the populations of the resident-poor states of California, Florida, and Texas grew by 10\%, 17.6\%, and $20.6 \%$, respectively, whereas the resident-rich states of New York, Massachusetts, and Pennsylvania grew only by $2.1 \%, 3.1 \%$, and $3.4 \%$, respectively (42). The current GME formula also results in substantial variation in the amount that is paid by Medicare per resident depending on the institution. Substantial inequalities also exist when this is viewed at the state level. For example, the average GME payment to institutions per resident ranges from $\$ 43908$ in Wyoming to \$155 135 in Connecticut (42). Although some degree of variation in GME payments is appropriate due to cost-of-living differences across geographic areas and other factors, this amount of variation warrants examination.

\section{Lack of Transparency}

Medicare GME funds go directly to teaching hospitals that sponsor training programs even if the hospitals do not directly incur all of the training costs. Some institutions have specific formulas for the distribution of GME funds, but others are subject to annual negotia- 
tions with departments, which could result in the use of funds for purposes not intended. Faculty who direct training programs often do not know how they are supported or whether they are receiving adequate support from Medicare (19). In addition, although hospitals are required to provide cost reports annually to the Centers for Medicare \& Medicaid Services, obtaining information on specific direct and indirect payments is sometimes problematic because of large variation in transparency and accountability. Information on the amount of funding provided through private sources and the true cost of training residents are also unclear.

\section{Variable Accountability to Government Funding of GME}

Currently, accountability for the substantial investment the federal government makes in GME varies. The Medicare Payment Advisory Commission, IOM, and others have recommended moving toward a GME payment system that fosters greater accountability for Medicare GME dollars and rewards programs that meet desired educational outcomes and standards. Data suggest that teaching hospitals have favored less costly, higher revenue-generating specialty training over primary care positions (35). The expansion of these programs over the past 10 years parallels losses in positions in primary care specialties.

\section{Need for More Flexibility to Allow for Innovative Models of Training}

As the health care delivery system evolves, a parallel evolution in the setting, content, and duration of training must also occur. Experimentation and adoption of innovative models of training are necessary to prepare future physicians with the skills necessary to practice in patient-centered medical homes, accountable care organizations, and other contemporary and interprofessional models of health care. Enabling residents to train in well-functioning ambulatory settings, specifically physician offices, will allow them to gain the skills necessary to care for the kinds of patients encountered in a typical office-based practice. Such training will require changes to GME funding, accreditation, and the culture of academic medicine. Systems-based practice, 1 of the 6 core competencies in the ACGME Next Accreditation System, defines an expectation that residency programs and trainees understand the changing face of health care delivery and work to improve systems to optimize patient care. Accomplishing this goal will require innovative models of training.

\section{IOM Report on the Governing and Financing of GME}

In July 2014, the IOM released the highly anticipated report, "Graduate Medical Education That Meets the Nation's Health Needs" (2), which calls for major restructuring of GME financing "to allow a transition to an accountable, performance-based system" to fund GME over the next 10 years.

\section{IOM Recommendations}

Recommendation 1: Maintain Medicare graduate medical education (GME) support at the current aggregate amount (i.e., the total of indirect medical education and direct graduate medical education expenditures in an agreed-on base year, adjusted annually for inflation) while taking essential steps to modernize GME payment methods based on performance, to ensure program oversight and accountability, and to incentivize innovation in the content and financing of GME. The current Medicare GME payment system should be phased out.

Recommendation 2: Build a graduate medical education (GME) policy and financing infrastructure.

2a. Create a GME Policy Council in the Office of the Secretary of the U.S. Department of Health and Human Services. Council members should be appointed by the Secretary and provided with sufficient funding, staff, and technical resources to fulfill the responsibilities listed below.

- Development and oversight of a strategic plan for Medicare GME financing;

- Research and policy development regarding the sufficiency, geographic distribution, and specialty configuration of the physician workforce;

- Development of future federal policies concerning the distribution and use of Medicare GME funds;

- Convening, coordinating, and promoting collaboration between and among federal agencies and private accreditation and certification organizations; and

- Provision of annual progress reports to Congress and the Executive Branch on the state of GME.

2b. Establish a GME Center within the Centers for Medicare \& Medicaid Services with the following responsibilities in accordance with and fully responsive to the ongoing guidance of the GME Council:

- Management of the operational aspects of GME Medicare funding;

- Management of the GME Transformation Fund (see Recommendation 3), including solicitation and oversight of demonstrations; and - Data collection and detailed reporting to ensure transparency in the distribution and use of Medicare GME funds. 
Recommendation 3: Create one Medicare graduate medical education (GME) fund with two subsidiary funds.

3a. A GME Operational Fund to distribute ongoing support for residency training positions that are currently approved and funded.

3b. A GME Transformation Fund to finance initiatives to develop and evaluate innovative GME programs, to determine and validate appropriate GME performance measures, to pilot alternative GME payment methods, and to award new Medicare-funded GME training positions in priority disciplines and geographic areas.

Recommendation 4: Modernize Medicare graduate medical education (GME) payment methodology.

4a. Replace the separate indirect medical education and direct GME funding streams with one payment to organizations sponsoring GME programs, based on a national per-resident amount (PRA) (with a geographic adjustment). $4 b$. Set the PRA to equal the total value of the GME Operational Fund divided by the current number of full-time equivalent Medicarefunded training slots.

4c. Redirect the funding stream so that GME operational funds are distributed directly to GME sponsoring organizations.

4d. Implement performance-based payments using information from Transformation Fund pilots.

Recommendation 5: Medicaid graduate medical education (GME) funding should remain at the state's discretion. However, Congress should mandate the same level of transparency and accountability in Medicaid GME as it will require under the changes in Medicare GME herein proposed. (2)

Our organizations have reviewed the report in detail, and although we support many elements of it, there are several areas of concern. We join the IOM in the call for innovation and transformation in GME, including a greater emphasis on training in communitybased settings. However, we are concerned that reducing GME payments to existing programs (by taking the expense of 2 new government offices and the Children's Hospitals GME payments out of a static GME fund) will devastate many teaching hospitals and the patients they serve who are in the greatest need of health care-those who disproportionately consist of the poor, minorities, and underserved persons. We agree with the IOM that it is critical that GME policy be aligned with the nation's workforce policies. Although we also agree that GME is a public good, we are dis- appointed that the IOM did not call for an all-payer GME financing system to support this public good.

Although not part of the recommendations, that the IOM stated that it "did not find credible evidence" (2) that the nation is facing a looming physician shortage, particularly in primary care specialties, is extremely concerning. Paradoxically, the IOM suggested that "GME funds might be used to finance new incentives for choosing a primary care career" (2), even as it questioned whether a primary care shortage exists. We concur with the IOM that more research is needed to guide physician workforce policies and that incentives, including payment reform, are needed to encourage careers in primary care, but we believe there is credible evidence of a real and growing shortage of primary care physicians for adults and other specialties that warrants immediate action.

Although workforce projections are unlikely to precisely predict shortages, the trends can serve as a guide in determining and preparing for future challenges. Several projections indicate a shortfall of physicians in both primary and specialty care (3-18). The IOM rejected the evidence of existing and looming shortages, stating that these predictions often assume historic provider-patient ratios. The IOM noted the need for a more coordinated, affordable, and patientcentered health care system and cited studies that considered models with expanded roles for advanced practice clinicians; redesign of care delivery; and other innovations in health care delivery, such as telehealth and electronic communication (44-47). Such a system would be ideal, but transformation will take time and it would be dangerous to make workforce decisions based on a model that has not been achieved or tested. For example, nurse practitioners and physician assistants have similar subspecialization trends seen in physicians and cannot be relied on to increase access to primary care (48).

Further, adoption of technology and increased use of telemedicine have had many obstacles, so widespread use is not guaranteed and will take time. Electronic health record (EHR) systems have the promise of improving patient care and practice efficiency, but the evidence suggests that these effects have not been realized. A 2015 report by AmericanEHR Partners and the American Medical Association based on a survey of physicians revealed that compared with 5 years ago, more physicians report being dissatisfied or very dissatisfied with their EHR system. Of note, $72 \%$ believed that decreasing the workload was difficult or very difficult to do with EHR use and $42 \%$ believed that improving efficiencies was difficult or very difficult with EHR use (49). In addition, the federal EHR incentive payment program designed to encourage physicians and health facilities to install EHRs has had many challenges, includ- 
ing delays and a decline in physician participation in the program's fourth year (50).

In its November 2014 report (51), the Council on Graduate Medical Education, an advisory body to the U.S. Department of Health and Human Services and Congress, reaffirmed its past findings that federal GME investments should increase above current levels and expressed reservations about proposals, including the IOM's, to redirect or cut existing investments (51). The Council on Graduate Medical Education urged "caution to suggestions that the supply of physicians in the training pipeline should be limited until there is evidence to judge the effectiveness of emerging practice models that rely on mid-level providers" (51). It also disagreed with the IOM's recommendation that funding should be limited to current levels and cited evidence of shortages in many specialties, including family medicine, geriatrics, general internal medicine, general surgery, and pediatric subspecialties. The Council on Graduate Medical Education also cautioned, "With the current increasing demand for health care services, missteps in GME policies could have long-lasting, detrimental effects on the physician workforce, cost, healthcare quality, access to medical services, and the patient experience" (51). Our organizations echo this warning and offer the following recommendations to ensure that the nation has an adequate supply of the types of physicians needed to treat patients; that they enter the workforce with the knowledge, skills, and attitudes required to provide the highest quality care; and that all Americans have access to such care.

\section{Positions}

1. The federal government should maintain its commitment to GME. Payment of Medicare GME funds should be linked to the ability of the GME system to meet the nation's health care workforce needs. Payments should be used to meet policy goals to ensure adequate supply, specialty mix, and training sites.

Our organizations believe that sufficient GME funding and a more strategic approach to its use are critical. Medicare's contribution to GME must be preserved. Although we agree that some of the costs covered by the IME adjustment have decreased, we also contend that other costs related to DGME expenditures have increased, primarily because of increased regulatory demands. The DGME reimbursement amounts were set in 1986 and have been adjusted only for inflation. Studies evaluating the costs of residency programs support higher DGME costs over time (52). In fact, the increase in DGME costs seems to roughly offset the decrease in IME costs, such that across the entire system, current reimbursement approximates actual costs of training residents (recognizing that significant variation exists across states and institutions). Substantial reductions in IME payments would result in a failure to cover neces- sary direct costs and could have a devastating effect on GME programs. Of note, these calculations were based on studies conducted in the early 2000s; a more recent study published in 2014 found substantially greater training costs that exceed the IME offset (53).

We also feel strongly that Medicare GME funds should be tied to the nation's health care workforce needs. We were encouraged by the establishment of the National Health Care Workforce Commission, which is charged with evaluating the nation's health care workforce needs and providing recommendations to Congress and the administration on national health workforce priorities, goals, and policies through The Patient Protection and Affordable Care Act. However, we are dismayed that this Commission has yet to receive funding to conduct its important work. The nation needs workforce policies that include sufficient support to educate and train a supply of health professionals that meets the nation's health care needs-policies that ensure an adequate supply and spectrum of primary care physicians trained to manage care for the whole patient.

The Association of American Medical Colleges projects a shortfall of between 46100 and 90400 physicians by 2025 . The shortage in the number of primary care physicians is estimated to range between 12500 and 31100 by 2025 (5). A report released by HRSA in November 2013 (6) also predicted a shortage of primary care physicians within this range, estimating a shortage of 20400 primary care physicians by 2020 (6). These projections are not as large as those that have been found in prior studies, yet they are still significant. In certain parts of the country, a shortage of primary care physicians already exists. The HRSA estimates that there are 6100 designated primary care health professional shortage areas, and it would take approximately 8200 additional primary care physicians to eliminate them (54).

We found significant evidence of geographic maldistribution of physicians $(55,56)$. Metropolitan areas have 84 primary care physicians per 100000 persons, whereas nonmetropolitan areas have 68 primary care physicians per 100000 persons (57). Specialists are even more concentrated, with more than 3 times the density of specialists in metropolitan than nonmetropolitan areas (58). Physicians tend to stay and work where they were trained, so Medicare GME dollars should be weighted to favor training programs in rural and underserved areas. Students from rural areas are more likely to practice there than those from urban areas (59). Weighting or shifting GME dollars to programs in areas where physicians are needed most might lead to an increase in training positions in underserved areas and a change in the distribution of physicians once their training is completed. 


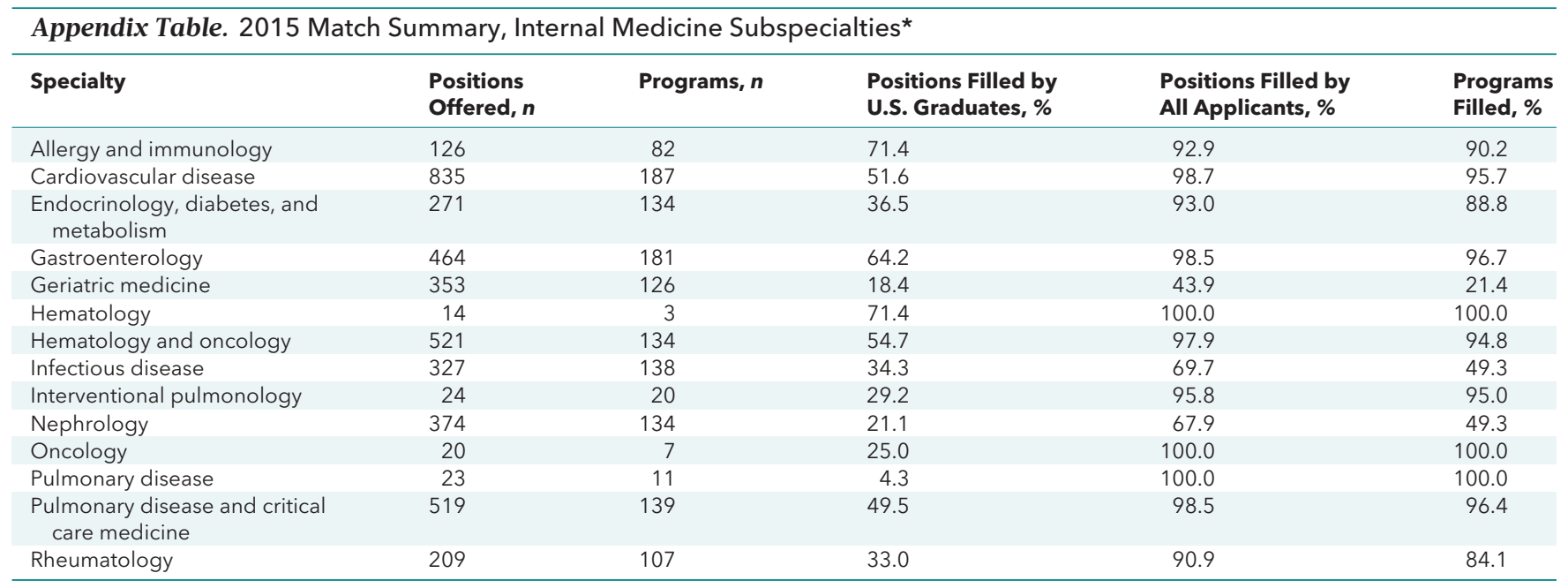

* Data obtained from reference 61 .

A thorough assessment of the supply, specialty mix, and distribution of physicians is necessary, and Medicare GME dollars should be used to address any shortcomings. This assessment should be a top priority for the National Healthcare Workforce Commission and the National Center for Health Workforce Analysis. We believe that workforce data should be used in a realtime, dynamic system to inform GME funding formulas. If the GME finance system is to act as a lever to affect the physician workforce, then the process by which it acts should be nimble and dynamic enough to respond to the changing priorities of our health care system. Further, this system should recognize the need that institutions and programs have for intermediate-range stability. It is important that state and regional needs are considered and that these entities have a role in the decision-making process.

The American Academy of Family Physicians has proposed limiting GME funding to first-certificate programs, which we cannot support because it would effectively eliminate all federal GME funding of nearly all internal medicine subspecialty fellowship training programs, including cardiology, critical care medicine, endocrinology, gastroenterology, geriatrics, hematology, infectious disease, nephrology, oncology, pulmonology, and rheumatology (60). Internal medicine and internal medicine-pediatrics training programs provide a strong foundation in clinical decision-making skills that can be applied in several settings, including complex and chronic illnesses. This patient-centered, high-value focus is important in primary care and subspecialty practices. Many internal medicine subspecialists serve as primary care physicians for their patients. All subspecialists are first trained in 3 years of core internal medicine, which prepares them with the diagnosis, management, and prevention of diseases that affect patients. The amount of primary care that subspecialists provide depends on various factors, including geogra- phy and practice type. Fellowship programs already receive only $50 \%$ of the DGME payment that firstcertificate programs receive, leaving teaching hospitals to cover the remainder. Many institutions are already strained by these costs, and elimination of such funding in internal medicine subspecialty training programs would undermine the goals of having well-trained physicians in these critically important subspecialty areas and contribute to a growing shortage of physicians in many of these fields. Cognitive subspecialties in particular are underfunded, and their pipeline is drying up quickly, which is illustrated by the 2015 appointment year fellowship data-56.1\% of geriatrics, $32.1 \%$ of nephrology, and $30.3 \%$ of infectious diseases programs went unfilled due to lack of applications (61) (Appendix Table). In addition, up to one third of physicianscientists who drive research and innovation come through the internal medicine subspecialty pipeline (62). Flexibility is internal medicine's strength, and as we produce physicians for an ever-changing health care system, internal medicine should be structured to draw persons into needed specialties.

2. All payers should be required to contribute to a financing pool to support residencies that meet the nation's policy goals related to supply, specialty mix, and training sites.

Our organizations feel strongly that the costs of financing GME should be spread across the health care system. Although Medicare and other federal programs should continue to make a substantial contribution to the financing of $\mathrm{GME}$, an all-payer system would ease the obligation on Medicare and taxpayers and provide a more stable and predictable funding stream. The supply and distribution of physicians affect the availability, cost, and quality of care for all Americans. As such, the cost should be borne by all payers of health care services-public and private. 
Graduate medical education serves a public good. It benefits all of society, not just persons who directly purchase or receive it. All payers depend on welltrained medical graduates, medical research, and technical advances from teaching hospitals to meet the nation's demand for high-quality care. All payers should be concerned that the nation's system of GME is preserved, high standards of quality for patient care services are maintained, and opportunities for entry into the medical profession are available to the most qualified candidates. A mechanism should be established to require all payers to explicitly contribute to GME.

3. A thorough evaluation of the true cost of training physicians is required before any decisions are made about how GME funds are distributed.

Except for inflation, the hospital-specific PRA has not been adjusted since 1983. Since then, much has changed in GME that has added to the cost of training, including program requirements mandated by the ACGME. For example, costs related to implementing duty hour changes have had a substantial effect on programs' funds $(63,64)$. In many programs, the GME costs are often subsidized by clinical practice, and as these dollars shrink, it will be challenging to function with a reduction in GME funds or cover the costs of additional unfunded mandates.

We believe that the current distribution of DGME and IME funds does not accurately reflect the expenses that they are intended to cover. Payment must be calibrated to the true costs of educating physicians in today's accreditation and clinical environment and be structured to account for any future changes so that funds are not held static while the costs of training increase.

4. Direct GME and IME should be combined into a single, more functional payment program that is designed to meet the needs of patients and populations.

Our organizations support the IOM's recommendation that Congress combine DGME and IME funds and establish a single PRA with a geographic adjustment. We believe that once the true cost of training a resident is determined and a single PRA is set, transparency will greatly improve.

5. Graduate medical education funding should be transparently allocated to ensure that funds are appropriately designated toward activities related to the educational mission of teaching and training residents and fellows. Graduate medical education funds should follow trainees into all training settings, rather than being linked to the location of service relative to the sponsoring institutions.

Our organizations strongly favor funding that "follows" trainees to settings outside the walls of the sponsoring institution, thus minimizing barriers to training sites that would broaden their experience and expose them to a greater variety of practice settings. Any rota- tion or experience that is approved by the training program and is consistent with accreditation standards should be eligible for Medicare reimbursement, regardless of the location.

We considered the option that IOM and others have proposed to pay training programs directly but determined that such action would not improve their quality. Individual residency programs generally lack the infrastructure to deal with such financial processes, and acquiring this resource would add overhead costs to residency training. In addition, programs have a budget and would probably be allocated costs by their institutions, which they would have to pay from GME funds. We believe the core issue is transparency. The entity to which the funds are distributed would be a nonissue if institutions had to fully account for how the dollars are dispersed to the programs and other pertinent entities. More flexibility is needed in how funds are used so that programs have the ability to use alternative "highly functioning" settings, recruit from excellent outpatient practices and other innovative ambulatory settings, and pay more equitably for faculty teaching time and resources required for training in various settings.

Further, although the term "accountability" has been tied to the notion that training programs and institutions should be responsible for producing the specialty spectrum and geographic distribution of physicians that are necessary to meet the nation's health care needs, we believe this expectation is unreasonable. National and regional workforce decisions should be guided by periodic rigorous analyses made on a national and regional level and promoted through specific funding mechanisms rather than metrics (as noted in our first position).

Medicare GME payment information should be made publicly available in a concise, timely, and easily accessible report to ensure that the funds are used for educating and training residents. We support an annually published report that clearly identifies each institution and training program, the GME payments received, the number of residents and other health professionals that Medicare supports, and Medicare's share of teaching costs incurred. Hospitals should show that funds flow to programs.

6. Graduate medical education caps should be lifted as needed to permit training an adequate number of primary care physicians, including internal medicine specialists, and physicians in other specialties facing shortages, including internal medicine-pediatrics and many internal medicine subspecialties.

Changing the way existing GME dollars are distributed is important, but Medicare limits on GME funding on residency training positions will continue to impede the establishment of new residency programs and additional training positions in existing programs. Medical 
schools have expanded class sizes by nearly $30 \%$ and are on track to meet enrollment increases that the Association of American Medical Colleges called for in 2006 to address the projected physician shortage (65). However, this will not increase the total number of U.S. physicians unless GME capacity is also increased. Our organizations believe that GME funding should be more effectively targeted and prioritized to fields with the greatest and most critical needs to train more physicians to meet national workforce goals, rather than asking the federal government to incur the much larger costs associated with a general or an undifferentiated expansion of residency positions.

The Affordable Care Act included provisions for a modest redistribution of unused residency slots with a priority for primary care, but this redistribution will not be enough to help meet the future demand for such physicians. To reform the nation's health care delivery system to better manage chronic conditions and keep a patient from requiring hospitalization, we need an adequate supply of primary care physicians who collaborate with subspecialists and other health professionals as part of a team to manage a patient's whole health. In addition, without an increase in residency positions, international medical graduates may be forced out of the U.S. health care system. More U.S. medical graduates will probably fill residency positions once filled by international medical graduates, leading to a potential reversal of gains made in reducing health professional shortage areas and a less culturally diverse physician population.

7. The concept of a performance-based GME payment system is worth exploring. Such a system should be thoughtfully developed and considered in a deliberate way to ensure that goals are achieved without destabilizing the system of physician training. We recommend the following:

a. Measures should be developed by appropriate stakeholders, including physicians involved in GME training.

b. All measures must be carefully developed and thoroughly evaluated before they are implemented.

c. Institutions must be allowed adequate time to make necessary changes to their training programs before financial incentives are introduced.

d. Revised GME funding should account for the costs of transitioning into a performance-based GME system, and once done, clear-cut financial transparency and incentives must be delineated.

e. The performance measures should be evidencebased and align with the ACGME requirements. The core mission of individual programs should be considered. Producing a certain number of physicians trained in a certain specialty or subspecialty should not be a specific performance metric. f. A careful study of unintended consequences should be done to ensure that programs are not unfairly disadvantaged.

g. Regular evaluations of the measures should be implemented to avoid adverse unintended consequences, ensure that the goals of implementing such a system are achieved, and confirm that the measures remain relevant over time.

In recent years, there have been several proposals to use a portion of GME dollars to establish a performance-based GME payment system in an effort to encourage greater accountability for Medicare's GME dollars and reward education and training that will improve the health care delivery system or meet the nation's workforce goals. Our organizations believe that the concept of a performance-based GME payment system is worth exploring, but caution that such a system must be thoughtfully developed using a sound research basis and evaluated with input from various stakeholders, including physicians involved in training. It should not be assumed that simply instituting performance metrics will result in improved medical education or progress toward workforce goals.

We feel strongly that immediate implementation of a performance-based GME payment system is premature without other substantial changes. Other than for inflation, GME funding has not been adjusted for some time while salary and other indirect costs of GME have increased. It would be difficult to think that such a program could be successfully implemented in a budgetneutral manner. In addition, it is critical that programs be given time to implement the measures. Of note, in stitutions have unique restrictions that affect their ability to change their programs, including accreditation requirements that preclude significant adjustment in administrative support (ratio of faculty to number of residents for all programs, and more detailed requirements for some disciplines for other types of clinical and nonclinical staff), contractual commitments to residents that are reinforced by accreditation that supersede "at-will" employment regulations in states and even require institutions to place currently contracted residents if they go out of business, rules stating that the size of programs cannot expand to meet workforce needs without documenting educational need and institutional resources and obtaining approval from accrediting bodies, and policies stating that institutions cannot increase the price of services in response to changes in demand and are legally obliged to provide emergency care to all who present to the emergency department.

Metrics should also be evidence-based to the extent possible. The evidence base available to inform changes to the financing of GME is extremely limited, and pilot projects are essential to mitigating unintended consequences. In addition, we believe that 
most GME funding should be based on accurate cost estimates and that payments based on performance metrics should make up a substantial portion (but less than the majority).

We do not recommend specific performance metrics in this policy position paper but have identified potential areas to be explored. These include high-value care, innovating ambulatory training, interprofessional models of care, and other new models of care. Hospitals and residency programs are already required to meet certain measures as part of the ACGME program and institutional requirements, the ACGME Clinical Learning Environment Review, and the competencybased ACGME milestones for their trainees. Although direct use of these formative measures would not be appropriate and would have unintended consequences that would undermine competency-based training, the variables that guide the Clinical Learning Environment Review and milestones data could inform a performance-based GME payment system. The AAIM has developed a GME Funding task force with the express purpose of proposing performance metrics in the following areas: care of the underserved; value in health care; patient safety; access to care; patientcentered care; educational environments; and communication, teamwork, and transitions of care. This task force will consider each of these performance categories across 4 perspectives: collective GME, institutions, programs, and trainees.

Several proposals to move toward a performancebased GME payment system have included a measure to increase the number of physicians in needed specialties and geographic locations, and some specify primary care as a metric. We caution that this is not a realistic metric because training programs cannot be held accountable for the career decisions of their trainees. Important factors for the career choice of medical students include perceived professional satisfaction of practitioners; lifestyle; and ability to pay off debt incurred for medical school, which now averages $\$ 176$ 348. In addition, the effect of our dysfunctional health care system, undergraduate medical education environment, family pressures, and professional goals are major determinants of the career decisions of young physicians. Unless there are other reforms (such as payment and practice reform) that draw persons into shortage fields or underserved geographic areas, changes to our GME finance system will probably have little effect. We believe that measures should go beyond workforce needs and instead hold programs accountable for ensuring that residents obtain durable skills that they will need when they start practice and confer flexibility in skills to lead and evolve as delivery systems change.

Flexibility and adaptability in measurement are necessary because not every program or institution has

www.annals.org the same core mission and patient population, and they should not be required to meet the same set of performance measures. Although some programs may focus on training residents in ambulatory primary care or highly specialized specialties, others may have a history of training the nation's best researchers. All of these clinicians will be needed to meet the nation's health care needs. We support a core set of measures with additional measures that are unique to the core mission of each program.

8. Pilot projects should be introduced to evaluate potential changes to GME funding, including a performance-based GME payment system, and to promote innovation in GME by providing training programs with the resources necessary to experiment with innovative training models. Pilot projects should not be funded using existing GME funding.

Our organizations believe that GME must continually improve and evolve to better meet the needs of society. We agree with the IOM that a transformation fund is needed with the goal of promoting innovation and achieving the triple aim of improving the experience of care, improving the health of populations, and reducing per capita costs of health care. However, we strongly oppose using existing GME dollars to fund these pilot projects because any reduction would be destabilizing to the nation's training programs. Instead, there should be a separate, dedicated source of funding for pilot projects and multisite educational outcomes research. Successful studies can then lead to wide application.

The nation cannot reform the health care delivery system without ensuring that future physicians have the skills necessary to coordinate care across settings, improve care quality, and use resources efficiently. Training should evolve to incorporate the coordinated care that patients want and need to improve the value of the health care delivery system. Our organizations believe that there is no single appropriate model for a training program, and programs should be encouraged to develop models that best fit the needs of the communities they serve.

In addition, any changes to the structure of GME funding, including a performance-based GME payment system, should be studied through pilot programs before implementation to help balance unintended consequences. To our knowledge, there is no evidence on the effects of implementing such a payment system.

An alternative to the IOM's proposed transformation fund is the establishment of a Center for Medical Education Innovation and Research, parallel to the Center for Medicare and Medicaid Innovation, with dedicated funding for pilot programs. If successful, such programs would then have wider dissemination in the GME community. We feel strongly that this would greatly enhance efforts to ensure that residents are 
trained with the necessary skills for the practice environment of the future.

9. Internal medicine and internal medicinepediatrics residents should receive primary care training in well-functioning ambulatory settings that are financially supported for their training roles. Barriers should be removed to encourage programs to train residents in nonhospital settings, promote innovation in training, and facilitate clinical learning experiences that promote primary care.

Internal medicine and internal medicine-pediatrics residents receive in-depth training in the prevention, diagnosis, and treatment of conditions that affect all organ systems. They are also trained to solve puzzling diagnostic problems and handle severe chronic illnesses and situations in which several illnesses may occur at the same time. Internal medicine residents are also trained in the essentials of primary care internal medicine, which incorporates an understanding of disease prevention, health promotion, substance abuse, and mental health. Internists are particularly focused on the care of adult and elderly patients with multiple complex chronic diseases. Internal medicine specialists provide long-term, comprehensive care in both the office and hospital. They manage both common and complex illnesses of adolescents, adults, and the elderly. It is essential that residents receive training in hospitals and various well-functioning ambulatory settings, including physician offices, geriatrics clinics, subacute rehabilitation and skilled nursing facilities, area health education centers, and community health centers. Exposure to the mix of patients typically seen in practice is also important during training.

The mix of patients typically seen by residents in internal medicine programs is heavily skewed toward those whose overall health is negatively affected by social determinants, including poverty, low literacy, and limited access to resources and safe housing. This effect can seem overwhelming to physicians-in-training who may not have the experience or resources to address their patients' medical and biopsychosocial needs. Residents might view careers in office-based general internal medicine more positively if they were exposed to a wider, more representative mix of patients and practiced in models with appropriate resources to address the effects of these social determinants. Ambulatory experiences should also mitigate against inpatient responsibility conflicts. One possible approach to this is to use ambulatory immersion systems.

Further, changes in health care delivery and the population's health have deemphasized hospital-based training, making it less relevant to some specialties. By exposing residents to well-functioning ambulatory settings, specifically physician offices, residents will be able to gain the skills necessary to care for the kinds of patients encountered in a typical office-based primary care practice.

The current requirement for ambulatory education for internal medicine residents is set at a minimum of $33 \%$ of overall residency training. The importance of considering a change in the amount of ambulatory training is highlighted in a recent study that showed a dramatic reduction in hospitalizations among Medicare beneficiaries from 1999 to 2013. Hospitalizations decreased from 35274 per 100000 beneficiaries to 26903 per 100000 beneficiaries, underscoring the need to continue to improve our trainees' outpatient experience and better prepare them for the health care system of tomorrow (66). We believe that internal medicine training programs should improve not only the quantity but also the quality of ambulatory training time. This may need to be encouraged through the regulatory or funding process. By establishing specific goals for training time spent in well-functioning ambulatory settings and ensuring "protected time" while in the ambulatory setting, internal medicine and other primary care residency programs can offer a more balanced and realistic experience. Although it is important for all programs to provide high-quality outpatient settings, there could be more flexibility around increasing the quantity of ambulatory training depending on individual program goals. For more outpatient-intense programs, GME payments should reflect their higher cost of training (53). In addition, mentorship programs should be encouraged and strengthened to ensure that residents are matched with practicing primary care physicians who can show them the many rewarding aspects of careers in general internal medicine and other primary care specialties.

Community-based training programs are 1 option to ensure more training in nonhospital ambulatory settings for primary care residents. The THC GME program, established through the Affordable Care Act, provides primary care medical and dental training opportunities in community-based settings. According to HRSA, physicians trained in health centers are more than 3 times as likely to work in a health center and more than 2 times as likely to work in an underserved area than those not trained at health centers. The program is administered and funded by HRSA rather than Medicare and is subject to appropriations. We believe it is important that this program continue and receive adequate and stable funding to support its mission. Community-based stakeholders have been reluctant to spend the time developing this program, only to see it lose funding. We also believe that the THC program should be modified so that it is more conducive to the participation of other primary care specialties (67). Funding for the THC program should not come out of existing Medicare GME funds but should be supported 
through mandatory appropriations or making THC funding permanent with additional GME funding.

\section{Web-Only References}

21. Accreditation Council for Graduate Medical Education. ACGME data resource book: 2013-2014. Chicago: Accreditation Council for Graduate Medical Education; 2014. Accessed at www.acgme.org /acgmeweb/tabid/259/Publications/GraduateMedicalEducation DataResourceBook.aspx on 10 September 2015.

22. Association of American Medical Colleges. How do teaching hospitals serve America's communities? Accessed at www.aamc.org /linkableblob/70256-3/data/teachhospfacts2-data.pdf on 22 September 2015.

23. Association of American Medical Colleges. Medicare direct graduate medical education (DGME) payments. Washington, DC: Association of American Medical Colleges; 2010.

24. Health policy briefs: graduate medical education. Bethesda, MD: Health Affairs; 2012. Accessed at www.healthaffairs.org/healthpolicy briefs/brief.php?brief_id=73 on 21 April 2016.

25. Association of American Medical Colleges. Medicaid graduate medical education payments: a 50-state survey. Washington, DC: Association of American Medical Colleges; 2013. Accessed at https: //members.aamc.org/eweb/upload/Medicaid\%20Graduate\%20 Medical\%20Education\%20Payments\%20A\%2050-State\%20Survey .pdf on 23 November 2015.

26. Kaufman A, Alfero C. A state-based strategy for expanding primary care residency. Bethesda, MD: Health Affairs Blog; 2015. Accessed at http://healthaffairs.org/blog/2015/07/31/a-state-based -strategy-for-expanding-primary-care-residency on 6 August 2015.

27. Pittman D. Residency slots: a crisis in the making? New York: MedPage Today; 2013. Accessed at www.medpagetoday.com /PublicHealthPolicy/MedicalEducation/42786 on 5 September 2015. 28. Health Resources and Services Administration; U.S. Department of Health and Human Services. Teaching Health Center Graduate Medical Education (THCGME). Accessed at http://bhpr.hrsa.gov /grants/teachinghealthcenters on 23 September 2015.

29. Wynn B, Guarino C, Morse L, Cho M. Alternative ways of financing graduate medical education. Washington, DC: RAND Health; 2006.

30. Accreditation Council for Graduate Medical Education. ACGME data resource book: 2014-2015. Chicago: Accreditation Council for Graduate Medical Education; 2015. Accessed at www.acgme.org /acgmeweb/tabid/259/GraduateMedicalEducation/GraduateMedical EducationDataResourceBook.aspx on 26 September 2015.

31. Centers for Medicare \& Medicaid Services. CMS cost reports: hospital Form 2552-10. Baltimore: Centers for Medicare \& Medicaid Services; 2014. Accessed at www.cms.gov/Research-Statistics-Data -and-Systems/Downloadable-Public-Use-Files/Cost-Reports/Hospital -2010-form.html on 5 September 2015.

32. Weida NA, Phillips RL Jr, Bazemore AW. Does graduate medical education also follow green? [Letter]. Arch Intern Med. 2010;170: 389-90. [PMID: 20177044] doi:10.1001/archinternmed.2009.529

33. 2015 annual report of the Boards of Trustees of the Federal Hospital Insurance and Federal Supplementary Medical Insurance trust funds. Baltimore: Centers for Medicare \& Medicaid Services; 2015. Accessed at www.cms.gov/research-statistics-data-and-systems /statistics-trends-and-reports/reportstrustfunds/downloads/tr2015.pdf on 25 September 2015.

34. American College of Physicians. How is a shortage of primary care physicians affecting the quality and cost of medical care? A comprehensive evidence review. Washington, DC: American College of Physicians; 2008.

35. Association of American Medical Colleges. Medical school graduation questionnaire: 2013 all schools summary report. Washington, DC: Association of American Medical Colleges; 2013. Accessed at www.aamc.org/download/350998/data/2013gqallschoolssummary report.pdf on 25 September 2015.

36. Schwartz MD, Durning S, Linzer M, Hauer KE. Changes in medical students' views of internal medicine careers from 1990 to 2007.

www.annals.org
Arch Intern Med. 2011;171:744-9. [PMID: 21518941] doi:10.1001 /archinternmed.2011.139

37. Association of American Medical Colleges. Medical student ed ucation: debt, costs, and loan repayment fact card. Washington, DC: Association of American Medical Colleges; 2014. Accessed at https: //members.aamc.org/eweb/upload/2014\%20DFC_\%20vertical.pdf on 22 September 2015.

38. Phillips RL, Dodoo MS, Petterson SM, Xierali I, Bazemore A, Teevan B, et al. Specialty and geographic distribution of the physician workforce: what influences medical student and resident choices? Washington, DC: Robert Graham Center; 2009. Accessed at www .graham-center.org/dam/rgc/documents/publications-reports /monographs-books/Specialty-geography-compressed.pdf on 21 April 2016.

39. Association of American Medical Colleges. 2015 state physician workforce data book. Washington, DC: Association of American Medical Colleges; 2015. Accessed at http://members.aamc.org /eweb/upload/2015StateDataBook\%20(revised).pdf on 23 February 2016.

40. Dorsey ER, Jarjoura D, Rutecki GW. Influence of controllable lifestyle on recent trends in specialty choice by US medical students. JAMA. 2003;290:1173-8. [PMID: 12952999]

41. Seifer SD, Vranizan K, Grumbach K. Graduate medical education and physician practice location. Implications for physician workforce policy. JAMA. 1995;274:685-91. [PMID: 7650819]

42. Mullan F, Chen C, Steinmetz E. The geography of graduate medical education: imbalances signal need for new distribution policies. Health Aff (Millwood). 2013;32:1914-21. [PMID: 24191080] doi:10 .1377/hlthaff.2013.0545

43. Henderson T. Population grows in South and West, slows in D.C. and North Dakota. The Washington Post. 11 January 2015. Accessed at on www.washingtonpost.com/politics/population-grows-in-south -and-west-slows-in-dc-and-north-dakota/2015/01/11/9789100e -99dc-11e4-bcfb-059ec7a93ddc_story.html 21 April 2016.

44. Altschuler J, Margolius D, Bodenheimer T, Grumbach K. Estimating a reasonable patient panel size for primary care physicians with team-based task delegation. Ann Fam Med. 2012;10:396-400. [PMID: 22966102] doi:10.1370/afm.1400

45. Green LV, Savin S, Lu Y. Primary care physician shortages could be eliminated through use of teams, nonphysicians, and electronic communication. Health Aff (Millwood). 2013;32:11-9. [PMID: 23297266] doi:10.1377/hlthaff.2012.1086

46. Auerbach DI, Chen PG, Friedberg MW, Reid R, Lau C, Buerhaus $\mathrm{Pl}$, et al. Nurse-managed health centers and patient-centered medical homes could mitigate expected primary care physician shortage. Health Aff (Millwood). 2013;32:1933-41. [PMID: 24191083] doi:10 $.1377 /$ hlthaff.2013.0596

47. Bodenheimer TS, Smith MD. Primary care: proposed solutions to the physician shortage without training more physicians. Health Aff (Millwood). 2013;32:1881-6. [PMID: 24191075] doi:10.1377/hlthaff 2013.0234

48. Petterson SM, Phillips RL Jr, Bazemore AW, Teevan Burke B, Koinis GT. Relying on NPs and PAs does not avoid the need for policy solutions for primary care. Am Fam Physician. 2013;88:230. [PMID: 23944725]

49. AmericanEHR; American Medical Association. Physicians use of EHR systems 2014. Naples, Florida: AmericanEHR; 2015. Accessed at www.americanehr.com/research/reports/Physicians-Use-of-EHR -Systems-2014.aspx on 4 September 2015.

50. Conn J. Meaningful use of EHRs by doctors fell in 2014. Modern Healthcare. 12 August 2015. Accessed at www.modernhealthcare .com/article/20150812/NEWS/150819976 on 10 September 2015. 51. Council on Graduate Medical Education. Twenty-second report: the role of graduate medical education in the new health care paradigm. Rockville, MD: Health Resources \& Services Administration; 2014. Accessed at www.hrsa.gov/advisorycommittees/bhpradvisory /cogme/Reports/22report.pdf on 23 September 2015.

52. Steinmann AF. Threats to graduate medical education funding and the need for a rational approach: a statement from the alliance 
for academic internal medicine. Ann Intern Med. 2011:155:461-4 [PMID: 21969344] doi:10.7326/0003-4819-155-7-201110040-00008 53. Ben-Ari R, Robbins RJ, Pindiprolu S, Goldman A, Parsons PE. The costs of training internal medicine residents in the United States. Am J Med. 2014;127:1017-23. [PMID: 25063649] doi:10.1016/j.amjmed .2014 .06 .040

54. Health Resources and Service Administration. Shortage designation: health professional shortage areas \& medically underserved areas/populations. Accessed at www.hrsa.gov/shortage on $17 \mathrm{Sep}-$ tember 2015.

55. Council on Graduate Medical Education. Physician distribution and health care challenges in rural and inner-city areas. Washington, DC: Health Resources and Services Administration; 1998.

56. Zhang X, Phillips RL Jr, Bazemore AW, Dodoo MS, Petterson SM, Xierali I, et al. Physician distribution and access: workforce priorities. Am Fam Physician. 2008;77:1378. [PMID: 18853533]

57. Petterson SM, Phillips RL, Bazemore AW, Koinis GT. Unequal distribution of the U.S. primary care workforce. Washington, DC: Robert Graham Center; 2013. Accessed at www.graham-center .org/rgc/publications-reports/publications/one-pagers/unequal -distribution-2013.html on 21 April 2016.

58. Government Accountability Office. Testimony before the U.S. Senate Committee on Health, Education, Labor, and Pensions, U.S. Senate: Primary care professionals: recent supply trends, projections, and valuation of services. GAO-08-472T. Washington, DC: Government Accountability Office; 2008. Accessed at www.gao.gov /new.items/d08472t.pdf on 15 September 2015.

59. Martin JC, Avant RF, Bowman MA, Bucholtz JR, Dickinson JR, Evans KL, et al; Future of Family Medicine Project Leadership Committee. The Future of Family Medicine: a collaborative project of the family medicine community. Ann Fam Med. 2004;2 Suppl 1:S3-32. [PMID: 15080220]

60. American Academy of Family Physicians. Aligning resources, increasing accountability, and delivering a primary care physician workforce for America. Shawnee, KS: American Academy of Family
Physicians; 2014. Accessed at www.aafp.org/dam/AAFP/documents /advocacy/workforce/gme/FullGME-090914.pdf on 21 April 2016.

61. National Resident Matching Program. Results and data: specialties matching service: 2015 appointment year. Washington, DC: National Resident Matching Program; 2015. Accessed at www.nrmp .org/wp-content/uploads/2015/02/Results-and-Data-SMS-2015.pdf on 25 September 2015.

62. Brass LF, Akabas MH, Burnley LD, Engman DM, Wiley CA, Andersen OS. Are MD-PhD programs meeting their goals? An analysis of career choices made by graduates of $24 \mathrm{MD}-\mathrm{PhD}$ programs. Acad Med. 2010;85:692-701. [PMID: 20186033] doi:10.1097/ACM $.0 \mathrm{~b} 013 \mathrm{e} 3181 \mathrm{~d} 3 \mathrm{ca} 17$

63. Nuckols TK, Bhattacharya J, Wolman DM, Ulmer C, Escarce JJ. Cost implications of reduced work hours and workloads for resident physicians. N Engl J Med. 2009;360:2202-15. [PMID: 19458365] doi: 10.1056/NEJMsa0810251

64. Nuckols TK, Escarce JJ. Cost implications of ACGME's 2011 changes to resident duty hours and the training environment. J Gen Intern Med. 2012;27:241-9. [PMID: 21779949] doi:10.1007/s11606 -011-1775-9

65. Association of American Medical Colleges. Medical school enrollment to approach 30 percent increase by 2019. Washington, DC: Association of American Medical Colleges; 2015. Accessed at www .aamc.org/newsroom/newsreleases/431036/20150430.html on 22 September 2015.

66. Krumholz HM, Nuti SV, Downing NS, Normand SL, Wang Y. Mortality, hospitalizations, and expenditures for the Medicare population aged 65 years or older, 1999-2013. JAMA. 2015;314:355-65. [PMID: 26219053] doi:10.1001/jama.2015.8035

67. Rieselbach RE, Feldstein DA, Lee PT, Nasca TJ, Rockey PH, Steinmann $A F$, et al. Ambulatory training for primary care general internists: innovation with the affordable care act in mind. J Grad Med Educ. 2014;6:395-8. [PMID: 24949177] doi:10.4300/JGME-D-14 $-00119.1$ 